\title{
Bacterial UDP-Glucose Hydrolases and P2 Receptor-Mediated Responses to Infection: A Commentary
}

\author{
Ifor R. Beacham ${ }^{1 *}$, John P. Headrick ${ }^{2}$ \\ ${ }^{1}$ Institute for Glycomics, Griffith University, Gold Coast Campus, Gold Coast, Australia; ${ }^{2}$ School of Medical Science, Griffith Uni- \\ versity, Gold Coast Campus, Gold Coast, Australia. \\ Email: *i.beacham@griffith.edu.au
}

Received March $7^{\text {th }}, 2013$; revised April $9^{\text {th }}, 2013$; accepted May $9^{\text {th }}, 2013$

Copyright (C) 2013 Ifor R. Beacham, John P. Headrick. This is an open access article distributed under the Creative Commons Attribution License, which permits unrestricted use, distribution, and reproduction in any medium, provided the original work is properly cited.

\begin{abstract}
UDP-glucose hydrolases are a group of relatively little known membrane-bound or periplasmic enzymes found in Salmonella enterica and E. coli. UDP-glucose is an agonist for a specific $\mathrm{P} 2$ receptor ( $\mathrm{P} 2 \mathrm{Y}_{14}$ ) found on epithelial cells and cells associated with innate immunity. It is also recognised as a 'danger signal'. Cells respond to mechanical damage by releasing UDP-glucose which activates $\mathrm{P}_{2} \mathrm{Y}_{14}$ to trigger an innate immune response; it is postulated that a similar response to bacterial infection may be protective against infection. However, the UDP-glucose hydrolases may constitute virulence factors able to abrogate this response by degradation of the released UDP-glucose.
\end{abstract}

Keywords: UDP-Glucose Hydrolase; $\mathrm{P}_{2} \mathrm{Y}_{14}$ Receptor; Virulence Factor; Salmonella enterica; E. coli

\section{Introduction}

Surface localised enzymes in bacteria are well known to be involved in mediating the utilisation of molecules, which otherwise cannot access the cytoplasm, as sources of carbon and energy. Classical examples include alkaline phosphatase, 5'-nucleotidase, lipases and proteases. In Gram-negative bacteria, such enzymes are located either in the periplasmic space, on the outer membrane, or are exported to the external milieu.

In Salmonella enterica and Escherichia coli, UDGglucose (UDPG) hydrolases were discovered as enzymes which catalyse the hydrolysis of the pyrophosphate bond of UDPG leading to the formation of UMP and glucose-1-phosphate [1,2]. In S. enterica, the enzyme (UshB) is located primarily in the inner membrane by virtue of a hydrophobic N-terminal topogenic sequence; it is in an $\mathrm{N}$-terminus inside/C-terminus outside orientation with enzyme activity accessible from the outside [1,3,4]. In $E$. coli and S. enterica, the enzyme (UshA) is periplasmic and also possesses 5 '-nucleotidase activity [1,2]. As well as differing in their cellular location, these enzymes display no sequence or antigenic similarities. Interestingly, whilst most $S$. enterica serotypes contain both activities, most serotype Typhimurium isolates contain an inactive

${ }^{*}$ Corresponding author. (cryptic) ushA allele [5-7]. Likewise, E. coli K-12 and natural isolates of $E$. coli contain no detectable membrane-associated UDP-glucose hydrolase activity [1] due to an inactive allele of $u s h B[5,8]$.

The role of the UDPG hydrolase (5'-nucleotidase) in $E$. coli, which has quite broad specificity for 5'- and other nucleotides, can be considered to be the degradation of external nucleotides enabling the uptake and use of nucleosides and phosphate [9]. A scavenging role for the Salmonella enzyme, with its narrower specificity for UDP-sugars, however, is not so clear. With the recent discovery of a class of P2 receptors for UDPG on the surface of eukaryotic cells, the role of UDPG hydrolases can be cast in a new light, relating to the cellular response to bacterial infection.

\section{P2Y Receptors and Nucleotide/UDPG Signalling}

Nucleotides in the form of adenine and uracil tri- and diphosphates have long been known to constitute signalling molecules in eukaryotic tissues, playing a role as endogenous "danger signals" following release from cells during injury, stress, infection or death [10]; concentrations of extracellular nucleotides can increase from $0.5-10 \mathrm{nM}$ to $>100 \mathrm{nM}$ following such events [11]. 
Their receptors, the P2 (purinergic) receptor family, are found on the surface of most animal tissues and fall into two families: The P2X family are ion channel receptors and the P2Y family comprise G-protein-coupled receptors. The P2Y family in mammals can be subdivided pharmacologically into adenine ( $\mathrm{P} 2 \mathrm{Y}_{1}, \mathrm{P}_{2} \mathrm{Y}_{12}$ and $\mathrm{P} 2 \mathrm{Y}_{13}$, ) or uracil-preferring $\left(\mathrm{P}_{2} \mathrm{Y}_{4}, \mathrm{P}_{2} \mathrm{Y}_{6}\right.$ and $\left.\mathrm{P}_{2} \mathrm{Y}_{14}\right)$ receptors. The $\mathrm{P}_{2} \mathrm{Y}_{14}$ receptor, a relatively recent addition to the $\mathrm{P} 2 \mathrm{Y}$ family, is notable since it is a specific receptor for UDPG and related sugar nucleotides [12,13], though UDP is also reported to be an agonist of the human receptor $[14,15]$. The intracellular concentration of UDPG is about $100 \mathrm{mM} \mathrm{[16]} \mathrm{and} \mathrm{mild} \mathrm{mechanical} \mathrm{stimulation}$ of a number of cell lines, by a change of medium, increases extracellular levels of UDPG to $1-20 \mathrm{nM}$ [17]. $\mathrm{P} 2 \mathrm{Y}_{14}$ has the highest expression in placenta, adipose tissue, stomach and intestine [12,13], and is highly expressed in the surface epithelial cells of other tissues such as lower respiratory tract and in enterocytes in mice [18]. The receptor is also expressed in rodent and human brain, localised to glial cells (specifically astrocytes), and is particularly apparent in immune cell types including neutrophils, lymphocytes and megakaryocytic cells [19]. Activation of $\mathrm{P} 2 \mathrm{Y}$ receptors by nucleotides involves a wide variety of responses [20,21], but of specific interest here is the regulation of the immune responses in response to UDPG, UDP and bacterial infection.

\section{P2Y Receptors and the Innate Immune Response}

Arase et al. [18] have shown that UDPG elicits innate mucosal immunity in the mouse female reproductive tract where its cognate receptor, $\mathrm{P}_{2} \mathrm{Y}_{14}$, is expressed in epithelial cells. UDPG up-regulates expression of $\mathrm{P} 2 \mathrm{Y}_{14}$ and stimulates IL-8 production, in human endometrial epithelial cells, leading to enhanced neutrophil chemotaxis. These results were shown to be $\mathrm{P}_{2} \mathrm{Y}_{14}$-dependent, with similar findings in mouse uterus. The $\mathrm{P}_{2} \mathrm{Y}_{14}$ receptor may also regulate chemotaxis of select bone-marrow derived hematopoietic stem cell populations [22], and mast cell function, a key to defence against Gram-negative bacteria [23], is also $\mathrm{P}_{2} \mathrm{Y}_{14}$ responsive [24]. Given that $\mathrm{P}_{2} \mathrm{Y}_{14}$ is expressed on the surface of a variety of tissues, Arase et al. propose a model for induction of innate immunity by microbial infection, or other insults, that extends to the lumen of other organs in addition to the FRT: damaged cells release UDPG into the lumen, upregulating $\mathrm{P}_{2} \mathrm{Y}_{14}$ in undamaged cells, with $\mathrm{P}_{2} \mathrm{Y}_{14}$ activation triggering IL-8 release and neutrophil recruitment. This response, in isolated human neutrophils, involves Rho-mediated signalling [25]. Thus UDPG may act as an endogenous "danger signal" (or one of a number of damage-associated molecular patterns or DAMPS) in an analogous fashion to bacterial pathogen-associated molecular patterns (PAMPs) which act via TLR receptors to provoke production of IL-8 and other cytokines. Maturation of dendritic cells (DCs) sensitive to PAMPs is $\mathrm{P}_{2} \mathrm{Y}_{14^{-}}$ dependent: the findings of Skelton et al. [26] suggest $\mathrm{P}^{2} \mathrm{Y}_{14}$ activation by UDP-glucose may initiate immune responses by promoting DC maturation. Curiously, alternate effects may arise in terms of viral responses: extracellular UDPG, UDP and UTP inhibit type I interferon production by virus-challenged plasmacytoid DCs, implicating involvement of $\mathrm{P}_{2} \mathrm{Y}_{14}$ (and/or P2Y4, P2Y6) receptors in down-regulating immune surveillance against viral infection [27].

Support for the above concept of UDP-glucose as an immune danger signal derives from work on $\mathrm{P}_{2} \mathrm{Y}_{6}$, whose agonist is UDP [20]. P2 $\mathrm{Y}_{6}$ (and P2Y14) is expressed in a murine macrophage-like cell line (RAW 264.7 cells), as well as peritoneal and bone marrow-derived macrophages. Activation of P2Y6 by UDP results in increased chemotaxis to splenocytes, peritoneal macrophages and RAW264.7 cells. In a peritonitis mouse model, intraperitoneal injection with UDP promoted clearance of E. coli, in contrast to mice treated with PBS or UDP plus a $\mathrm{P}_{2} \mathrm{Y}_{6}$ antagonist. Similarly, and remarkably, mice treated with UDP showed greatly increased survival when challenged with E. coli.

\section{UDP-Glucose Hydrolases as Bacterial Virulence Factors}

Rather than a purely catabolic role, these observations suggest a new role for UDPG hydrolases and 5'-nucleotidase: Clearly abrogation of the innate immune response to bacterial infection would advantage growth of invading bacteria, and could be effected by degradation of released UDPG to limit $\mathrm{P}_{2} \mathrm{Y}_{14}$ signalling. Likewise, UDPG-hydrolase-5' -nucleotidase could perform a similar role with respect to $\mathrm{P}_{2} \mathrm{Y}_{6}$ signalling since UDP is also a good substrate for the nucleotidase function of this enzyme [2], in addition to 5'-nucleotides and UDP-sugars. Significantly, UDP-sugars, in contrast to nucleotides, are resistant to degradation by eukaryotic ecto-nucleotidases and therefore constitute a stable endogenous signal [25], albeit susceptible to degradation by bacterial UDPG-hydrolases. Thus, these latter enzymes may be postulated to constitute virulence factors. Infection experiments, in vitro or in vivo, with isogenic mutant and wild-type strains of S. enterica or E. coli, either lacking, containing or overexpressing UDPG hydrolase (S. enterica) or UDPG hydrolase-5'-nucleotidase (E. coli), would answer this question. Accumulation of released nucleotides should be greater, and the innate immune response enhanced, in enzyme deficient strains, and vice versa for enzyme overexpressing strains. Differences between innate immune responses to infection with isogenic bacterial strains should be at least of similar magnitude to those obtained with or 
without P2 receptor antagonists; if there is receptor (and signalling) cross-talk, then the isogenic strain comparison might be particularly marked as compared to the use of receptor specific antagonists.

$\mathrm{P}_{2} \mathrm{Y}_{14}$ is expressed in the brain in humans and mice $[12,19,28]$. The rat homologue, VTR15-20, is also expressed in astrocytoma and neuronal cell lines and in rat primary astrocytes and microglia; in the latter, it is upregulated following challenge with zymosan, a stimulator of macrophage phagocytosis [29]. Up-regulation was also seen in discrete brain regions following in vivo challenge with LPS $[19,29]$. Rat primary astrocytes respond to UDPG with increases in intracellular $\mathrm{Ca}^{2+}[30]$. In view of the importance of glial cells in an immunological response to infection [31], such observations suggest that $\mathrm{P}_{2} \mathrm{Y}_{14}$, and possibly other related receptors, such as $\mathrm{P}_{2} \mathrm{Y}_{6}$, may be important in an innate immune response to infection within the brain [19]. Kinoshita et al. also recently reported constitutive $\mathrm{P}_{2} \mathrm{Y}_{14}$ activity in glial cells (astrocytes), regulating TNF- $\alpha$ release and subsequent MMP-9 activity [32]. Gram-negative bacteria are amongst those that can infect brain via either the bloodbrain barrier or the olfactory route of infection [33-36]. It is possible that they possess UDPG-hydrolases and/or nucleotidases, unrelated to those in enteric bacteria, that may counter this intrinsic defence pathway.

Should further studies substantiate the roles of bacterial UDPG-hydrolases and/or 5'-nucleotidases as virulence factors in pathogenic S. enterica and E. coli, the question arises as to whether selection is "coincidental" or "direct" [37]. S. enterica and E. coli can exist in other growth environments, both environmental [38] and animal hosts other than human. As zoonotic or environmental opportunists [37], and in view of the capacity of UDP-sugar hydrolases for using substrates as a carbon and energy source, it is therefore very plausible that, as postulated virulence factors, they are pre-adapted for survival in the external environment (e.g. water, food), or possibly during carriage and growth in animal hosts. Thus they could be considered as coincidental virulence factors [37]. This argument is more likely for UDPGhydrolase (5'-nucleotidase), which can recycle nucleotides, than for the unrelated UshB, of S. enterica which is a specific UDP-sugar hydrolase. The latter could quite possibly be directly selected as a virulence factor in the human host. Their dual use in different environments may be a factor in the silencing by missense mutation of ushA in certain natural isolates of S. enterica Typhimurium if use is required more consistently in a human or animal host over time, and not required (selected) in the external environment [6]. This may also be the case for other coincidental virulence factors since silencing by missense mutation is not revealed by sequence analysis alone.

\section{Concluding Remarks}

The role of $\mathrm{P} 2 \mathrm{Y}$ receptors in immune modulation is now well established. It is inherently likely that certain bacterial pathogens will have some capacity to counter this defence mechanism. Whilst catabolic UDPG-hydrolases and 5'-nucleotidases may at first seem unlikely candidates for such a role, we suggest that they are indeed likely virulence factors since their substrates are involved in immune modulation. The known existence of virulence factors that are pre-adapted in alternate growth environments, in opportunistic pathogens, is also consistent with such a role, at least in the case of a UDPG-hydrolase with 5'-nucleotidase activity.

\section{Outstanding Questions}

Can the release of nucleotides including UDPG, and the innate immune response be demonstrated in response to infection by $E$. coli or S. enterica infection in vitro?

Are the levels of released nucleotides and the magnitude of the innate immune response in the presence of infection by $S$. enterica or E. coli response increased in isogenic enzyme deficient strains?

Are the levels of released nucleotides and the magnitude of the innate immune response in the presence of infection response decreased in isogenic enzyme overproducing strains?

Is the survival of mice in response to infection by $E$. coli and $S$. enterica modulated by $u s h A / B$ deficiency or over-expression, hence replicating results with $E$. coli and UDP administration?

What is the relationship between the presence of active or inactive alleles of $u s h A$ or $u s h B$ and the pathogenicity of $E$. coli and $S$. enterica strains? Will active membraneassociated UDPG-hydrolase (UshB) be found in clinical isolates of $E$. coli?

Is the P2Y mechanism of up-regulation of innate immunity of particular relevance in the response to bacterial (or viral) infection in the brain?

\section{REFERENCES}

[1] L. Glaser, A. Melo and R. Paul, "Uridine Diphosphate Sugar Hydrolase. Purification of Enzyme and Protein Inhibitor," Journal of Biological Chemistry, Vol. 242, No. 8, 1967, pp. 1944-1954.

[2] H. C. Neu, "The 5'-Nucleotidase of Escherichia coli. I. Purification and Properties," Journal of Biological Chemistry, Vol. 242, No. 17, 1967, pp. 3896-3904.

[3] A. R. Garrett, L. A. Johnson and I. R. Beacham, "Isolation, Molecular Characterization and Expression of the UshB Gene of Salmonella typhimurium which Encodes a Membrane-Bound UDP-Sugar Hydrolase," Molecular Microbiology, Vol. 3, No. 2, 1989, pp. 177-186. doi:10.1111/j.1365-2958.1989.tb01806.x 
[4] R. A. Jones, D. M. Burns, D. J. Carruthers and I. R. Beacham, "Membrane Localisation of a UDP-Sugar Hydrolase, in Salmonella, Is by an Uncleaved N-Terminal Signal Peptide," FEMS Microbiology Letters, Vol. 114, No. 3, 1993, pp. 299-304. doi:10.1111/j.1574-6968.1993.tb06589.x

[5] C. J. Edwards, D. J. Innes, D. M. Burns and I. R. Beacham, "UDP-Sugar Hydrolase Isozymes in Salmonella enterica and Escherichia coli: Silent Alleles of ushA in Related Strains of Group I Salmonella Isolates, and of $u s h B$ in Wild-Type and K12 Strains of E. coli, Indicate Recent and Early Silencing Events, Respectively," FEMS Microbiology Letters, Vol. 114, No. 3, 1993, pp. 293-298. doi:10.1111/j.1574-6968.1993.tb06588.x

[6] D. Innes, I. R. Beacham, C. A. Bevan, M. Douglas and M. W. Laird, "The Cryptic UshA Gene (UshA(c)) in Natural Isolates of Salmonella enterica (Serotype Typhimurium) Has Been Inactivated by a Single Missense Mutation," Microbiology, Vol. 147, Pt. 7, 2001, pp. 1887-1896.

[7] D. M. Burns and I. R. Beacham, "Identification and Sequence Analysis of a Silent Gene (ush $A^{0}$ ) in Salmonella typhimurium," Journal of Molecular Biology, Vol. 192, No. 2, 1986, pp. 163-175.

doi:10.1016/0022-2836(86)90358-X

[8] W. Schroder, M. Burger, C. Edwards, M. Douglas and D. Innes, "The Escherichia coli Orthologue of the Salmonella ushB Gene (ushB(c)) Produces Neither UDP-Sugar Hydrolase Activity Nor Detectable Protein, But Has an Identical Sequence to That of Escherichia coli cdh," FEMS Microbiology Letters, Vol. 203, No. 1, 2001, pp. 63-68. doi:10.1111/j.1574-6968.2001.tb10821.x

[9] E. Yagil and I. R. Beacham, "Uptake of Adenosine 5'Monophosphate by Escherichia coli," Journal of Bacteriology, Vol. 121, No. 2, 1975, pp. 401-405.

[10] M. P. Abbracchio, G. Burnstock, J. M. Boeynaems, E. A. Barnard and J. L. Boyer, "International Union of Pharmacology LVIII: Update on the P2Y G Protein-coupled Nucleotide Receptors: From Molecular Mechanisms and Pathophysiology to Therapy," Pharmacological Reviews, Vol. 58, No. 3, 2006, pp. 281-341. doi:10.1124/pr.58.3.3

[11] E. R. Lazarowski, R. C. Boucher and T. K. Harden, "Mechanisms of Release of Nucleotides and Integration of Their Action as P2X- and P2Y-Receptor Activating Molecules," Molecular Pharmacology, Vol. 64, No. 4, 2003, pp. 785-795. doi:10.1124/mol.64.4.785

[12] J. K. Chambers, L. E. Macdonald, H. M. Sarau, R. S. Ames and K Freeman, "A G Protein-Coupled Receptor for UDP-Glucose," Journal of Biological Chemistry, Vol. 275, No. 15, 2000, pp. 10767-10771. doi:10.1074/jbc.275.15.10767

[13] M. P. Abbracchio, J. M. Boeynaems, E. A. Barnard, J. L. Boyer and C. Kennedy, "Characterization of the UDPGlucose Receptor (Re-Named Here the P2Y14 Receptor) Adds Diversity to the P2Y Receptor Family," Trends in Pharmacological Sciences, Vol. 24, No. 2, 2003, pp. 5255. doi:10.1016/S0165-6147(02)00038-X

[14] R. L. Carter, I. P. Fricks, M. O. Barrett, L. E. Burienek and Y Zhou, "Quantification of Gi-mediated Inhibition of Adenylyl Cyclase Activity Reveals That UDP Is a Potent
Agonist of the Human P2Y14 Receptor," Molecular Pharmacology, Vol. 76, No. 6, 2009, pp. 1341-1348. doi:10.1124/mol.109.058578

[15] A. Das, H. Ko, L. E. Burienek, M. O. Barrett and T. K. Harden, "Human P2Y(14) Receptor Agonists: Truncation of the Hexose Moiety of Uridine-5'-Diphosphoglucose and Its Replacement with Alkyl and Aryl Groups," Journal of Medicinal Chemistry, Vol. 53, No. 1, 2010, pp. 471-480. doi:10.1021/jm901432g

[16] M. R. Laughlin, W. A. Petit Jr., J. M. Dizon, R. G. Shulman and E. J. Barrett, "NMR Measurements of in Vivo Myocardial Glycogen Metabolism," Journal of Biological Chemistry, Vol. 263, No. 5, 1988, pp. 2285-2291.

[17] E. R. Lazarowski, D. A. Shea, R. C. Boucher and T. K. Harden, "Release of Cellular UDP-Glucose as a Potential Extracellular Signaling Molecule," Molecular Pharmacology, Vol. 63, No. 5, 2003, pp. 1190-1197. doi:10.1124/mol.63.5.1190

[18] T. Arase, H. Uchida, T. Kajitani, M. Ono and K. Tamaki, "The UDP-Glucose Receptor P2RY14 Triggers Innate Mucosal Immunity in the Female Reproductive Tract by Inducing IL-8," Journal of Immunology, Vol. 182, No. 11, 2009, pp. 7074-7084. doi:10.4049/jimmunol.0900001

[19] D. J. Moore, P. R. Murdock, J. M. Watson, R. L Faull and H. J. Waldvogel, "PR105, a Novel Gi/o-Coupled UDPGlucose Receptor Expressed on Brain Glia and Peripheral Immune Cells, Is Regulated by Immunologic Challenge: Possible Role in Neuroimmune Function," Brain Research Molecular Brain Research, Vol. 118, No. 1-2, 2003, pp. 10-23. doi:10.1016/S0169-328X(03)00330-9

[20] Z. Zhang, Z. Wang, H. Ren, M. Yue and K. Huang, "P2Y(6) Agonist Uridine 5'-Diphosphate Promotes Host Defense against Bacterial Infection via Monocyte Chemoattractant Protein-1-Mediated Monocytes/Macrophages Recruitment," Journal of Immunology, Vol. 186, No. 9, 2011 pp. 5376-5387. doi:10.4049/jimmunol.1002946

[21] W. G. Junger, "Immune Cell Regulation by Autocrine Purinergic Signalling," Nature Reviews Immunology, Vol. 11, No. 3, 2011, pp. 201-212. doi:10.1038/nri2938

[22] B. C. Lee, T. Cheng, G. B. Adams, E. C. Attar and N. Miura, "P2Y-Like Receptor, GPR105 (P2Y14), Identifies and Mediates Chemotaxis of Bone-Marrow Hematopoietic Stem Cells," Genes \& Gevelopment, Vol. 17, No. 13, 2003, pp. 1592-1604. doi:10.1101/gad.1071503

[23] T. Matsuguchi, "Mast Cells as Critical Effectors of Host Immune Defense against Gram-Negative Bacteria," Current Medicinal Chemistry, Vol. 19, No. 10, 2012, pp. 1432-1442. doi:10.2174/092986712799828319

[24] Z. G. Gao, Y. Ding and K. A. Jacobson, "UDP-Glucose Acting at P2Y14 Receptors Is a Mediator of Mast Cell Degranulation," Biochemical Pharmacology, Vol. 79, No. 6, 2010, pp. 873-879. doi:10.1016/j.bcp.2009.10.024

[25] J. I. Sesma, S. M. Kreda, N. Steinckwich-Besancon, H. Dang and R. Garcia-Mata, "The UDP-Sugar-Sensing P2Y(14) Receptor Promotes Rho-Mediated Signaling and Chemotaxis in Human Neutrophils," American Journal of Physiology and Cell Physiology, Vol. 303, No. 5, 2012, pp. C490-C498. doi:10.1152/ajpcell.00138.2012

[26] L. Skelton, M. Cooper, M. Murphy and A. Platt, "Human 
Immature Monocyte-Derived Dendritic Cells Express the G Protein-Coupled Receptor GPR105 (KIAA0001, P2Y14) and Increase Intracellular Calcium in Response to Its Agonist, Uridine Diphosphoglucose," Journal of Immunology, Vol. 171, No. 4, 2003, pp. 1941-194.

[27] A. Shin, T. Toy, S. Rothenfusser, N. Robson and J. Vorac, "P2Y Receptor Signaling Regulates Phenotype and IFNAlpha Secretion of Human Plasmacytoid Dendritic Cells," Blood, Vol. 111, No. 6, 2008, pp. 3062-3069. doi:10.1182/blood-2007-02-071910

[28] K. Freeman, P. Tsui, D. Moore, P. C. Emson and L. Vawter, "Cloning, Pharmacology, and Tissue Distribution of GProtein-Coupled Receptor GPR105 (KIAA0001) Rodent Orthologs," Genomics, Vol. 78, No. 3, 2001, pp. 124-128. doi:10.1006/geno.2001.6662

[29] M. E. Charlton, A. S. Williams, M. Fogliano, P. M. Sweetnam and R. S. Duman, "The Isolation and Characterization of a Novel G Protein-Coupled Receptor Regulated by Immunologic Challenge," Brain Research, Vol. 764, No. 1-2, 1997, pp. 141-148. doi:10.1016/S0006-8993(97)00438-1

[30] M. Fumagalli, R. Brambilla, N. D’Ambrosi, C. Volentéand M. Matteoli, "Nucleotide-Mediated Calcium Signaling in Rat Cortical Astrocytes: Role of P2X and P2Y Receptors," Glia, Vol. 43, No. 3, 2003, pp. 218-203. doi:10.1002/glia. 10248

[31] S. Rivest, "Regulation of Innate Immune Responses in the Brain," Nature Reviews Immunology, Vol. 9, No. 6, 2009, pp. 429-439. doi:10.1038/nri2565

[32] M. Kinoshita, K. Nasu-Tada, K. Fujishita, K. Sato and S. Koizumi, "Secretion of Matrix Metalloproteinase-9 from
Astrocytes by Inhibition of Tonic P2Y(14)-Receptor-Mediated Signal(s)," Cellular and Molecular Neurobiology, Vol. 33, No. 1, 2013, pp. 47-58. doi:10.1007/s10571-012-9869-4

[33] S. J. Owen, M. Batzloff, F. Chehrehasa, A. Meedeniya and Y. Casart, "Nasal-Associated Lymphoid Tissue and Olfactory Epithelium as Portals of Entry for Burkholderia pseudomallei in Murine Melioidosis" Journal of Infectious Diseases, Vol. 199, No. 12, 2009, pp. 1761-1770. doi: $10.1086 / 599210$

[34] F. W. van Ginkel, J. R. McGhee, J. M. Watt, A. Campos-Torres and L. A. Parish, "Pneumococcal Carriage Results in Ganglioside-Mediated Olfactory Tissue Infection," Proceedings of the National Academy of Science of America United States, Vol. 100, No. 24, 2003, pp. 14363 14367. doi:10.1073/pnas.2235844100

[35] K. S. Kim, "Mechanisms of Microbial Traversal of the Blood-Brain Barrier," Nature Reviews Microbiology, Vol. 6, No. 8, 2008, pp. 625-634. doi:10.1038/nrmicro1952

[36] K. Kristensson, "Microbes' Roadmap to Neurons," $\mathrm{Na}$ ture Reviews Neuroscience, Vol. 12, No. 6, 2011, pp. 345357. doi:10.1038/nrn3029

[37] S. P. Brown, D. M. Cornforth and N. Mideo, "Evolution of Virulence in Opportunistic Pathogens: Generalism, Plasticity, and Control," Trends in Microbiology, Vol. 20, No. 7, 2012, pp. 336-342. doi:10.1016/j.tim.2012.04.005

[38] J. L. Thomas, R. M. Slawson and W. D. Taylor, "Salmonella Serotype Diversity and Seasonality in Urban and Rural Streams," Journal of Applied Microbiology, Vol. 114, No. 3, 2012, pp. 907-922. doi:10.1111/jam.12079 